\title{
EFFECT OF OSTEON II COLLAGEN WITH HYALURONIC ACID ON OSSEOINTEGRATION OF SIMULTANEOUS PLACED IMPLANT IN PIEZOELECTRIC SPLITTED POSTERIOR MANDIBULAR ALVEOLAR RIDGE (CLINICAL AND RADIOGRAPHIC STUDY)
}

\author{
Abdel Aziz Baiomy Abdullah Baiomy*
}

\begin{abstract}
Aim: The present study was designed to estimate clinically and radiographically effect of Osteon II Collagen with Hyaluronic Acid on osseointegration of simultaneous placed implant in posterior mandibular alveolar ridge after piezoelectric ridge splitting technique (RST) .

Patients \& methods: This study was carried out on twenty one patients with partial edentulous narrow posterior mandibular alveolar ridge. Patients were divided randomly into three equal groups (group I treated by piezoelectric RST and simultaneous implant placement into their ridge; without any bone graft, group II treated by piezoelectric RST and simultaneous implant placement into their ridge which was grafted by Osteon II Collagen, while group III treated by piezoelectric RST and simultaneous implant placement into their ridge; associated with placement of Osteon II Collagen when mixed with Hyaluronic Acid in splitted alveolar ridge. Alveolar ridge in all group covered by guided tissue regeneration membrane after implant placement and bone grafting. Patients were evaluated clinically to assess probing depth (PPD), and implant stability quotient (ISQ) then radiographically to assess alveolar ridge width, marginal bone level (MBL), and bone density measurement $(\mathrm{BD})$ parameters at 3,6,9 \&12 months.
\end{abstract}

Results: Statistical analysis of PPD and ISQ results showed no significant difference between groups at the different intervals while MBL values showed that there is high statistical significant difference during 12 month interval when comparing group III vs. group II. On the same side, BD results showed that group III had highly statistical significant difference at all intervals when it was compared with group I. and at 6,9 and 12 months when comparing G III vs. G II.

Conclusion: The present study concluded that Osteon II Collagen with Hyaluronic Acid may be adjunctive tool to accelerate bone osseointegration around immediate placed dental implant in posterior mandibular alveolar ridge after piezoelectric ridge splitting technique.

* Ass. Professor of Oral and Maxillofacial Surgery, Faculty of Dental Medicine (Assiut) - Al-Azhar University 


\section{INTRODUCTION}

One of the most common challenges in dental field is bone resorption after tooth extraction. The bone resorption pattern after tooth extraction may jeopardize correct implant placement with respect to position and angulation. Malpositioned implants may affect the emergence profile of the final implant restoration and generate functional and esthetic problems that would have a negative effect on implant long-term success rate ${ }^{(1-3)}$.

Therefore, several trials were made to solve the problem of implant insertion in narrow alveolar ridge. Onlay lateral ridge bone grafting, horizontal osteo-distraction, and guided bone regeneration (GBR) techniques have been utilized for correction of defective ridges. However none of these trials have fulfilled the requirements of successful increase width in narrow ridge ${ }^{(4-6)}$.

One of methods which were developed to increase width of narrow ridge is crest split augmentation technique with simultaneous insertion of dental implants. It has several advantages such as reducing waiting time from surgery to beginning of prosthetic treatment, requiring fewer amounts of bone grafts, and preventing the collapse of distended buccal and lingual/palatal walls ${ }^{(7,8)}$. Although, RST is a way to solve the problem of the width in narrow ridges. It needs bone grafting procedure to fill up round the implant within created gap and promote the healing process ${ }^{(9-11)}$. Moreover, RST have certain limitations such as buccal plate resorption ${ }^{(12)}$, gingival recession, and devitalization of the out-fractured segment with subsequent facial bone loss/resorption ${ }^{(13,14)}$.

Among various bone graft materials which used in RST, calcium phosphate bone substitutes have been widely used due to their chemical similarity to human bone. Osteon II is one of alloplastic materials composed of hydroxyapatite $70 \%$ and betatricalcium phosphate $30 \%$ which are most close to major mineral components of human bone. It is osteoconductive material that acts as bone growth scaffold. It has interconnected porosity structure which is similar to that of human cancellous bone ${ }^{(15,16)}$. Collagen can be added to osteon II to allow easy manipulation and shaping during grafting procedure and to increase the osteoconductivity of Osteon II such as presenting in Osteon II collagen which composed of synthetic bone graft and bovine type I collagen ${ }^{(17)}$.

Recently, several researchers reported that Hyaluronic acid (HyA) capable to accelerate the onset of new bone formation when it is added to alloplastic bone graft for bone augmentation of alveolar defects. Where, HyA increases osteoblastic bone formation through increased mesenchymal cell differentiation and migration ${ }^{(18-20)}$. Accordingly, adding of HyA to Osteon II collagen could be a valuable in promoting bone healing in the splitted area and osseointegration around dental implant.

Therefore, the present study was atrial to assess effect of a mixture of HyA with Osteon II collagen on osseointegration of dental implant placement which immediately placed in piezoelectric ridge splitted narrow posterior mandibular alveolar ridge.

\section{PATIENTS AND METHODS}

\section{I- Patients Selection}

This study was carried out on twenty one patients (14males and 7 females, mean age of 37.5 years) with partial edentulous narrow posterior mandibular alveolar ridge (fig.1a). All patients were selected from those patients attending at the out-patients clinic of the Department of Oral and Maxillofacial Surgery in the Faculty of Dental Medicine, AlAzhar University, Assiut Branch.

Informed consent was obtained from all patients before any study procedures were performed. All patients were undergone for clinical examination and radiographic evaluation by CBCT (Kodak 9500 cone beam 3D system). 


\section{Patients Exclusion criteria:}

- Systemically healthy patients with edentulous posterior mandibular area.

- Preoperative CBCT readings revealing crestal ridge width of $3 \mathrm{~mm}$ and at least $8 \mathrm{~mm}$ in the corono-apical height from major anatomical features.

- The recipient site of the implant should be free from any pathological conditions.

\section{Patients Exclusion criteria:}

1. Presence of active infection around the failing tooth.

2. A medical history that would complicate the outcome of the study.

3. Dental history of bruxism, parafunctional habit, and/or lack of stable posterior occlusion.

4. Perforation and/or loss of labial bony plate following tooth removal and/or implant osteotomy.

5. Smoking patients

\section{Patients grouping and randomization:}

Patients classified randomly into the following equal groups using online software (https://www. randomizer.org):

1- Group I: treated by piezoelectric ridge splitting technique and simultaneous implant placement into their ridge; without any bone graft. Only it was covered by collagen membrane (GENOSS, Dentium. Co. Ltd, Suwon, South Korea).

2- Group I: treated by piezoelectric ridge splitting technique and simultaneous implant placement into their ridge; associated with osteon II collagen (GENOSS, Dentium. Co. Ltd, Suwon, South Korea) grafting and covered by collagen membrane.
3- Group III: treated by piezoelectric ridge splitting technique and simultaneous implant placement into their ridge; associated with osteon II collagen mixed with HyA (Hyadent, BioScience GmbH -Germany) and covered by collagen membrane.

\section{Pre-Surgical preparation:}

Each patient was receive prophylactic antibiotic (Augmentin 1gm tablet, GlaxoSmithKline, Fifth district, New Cairo, Cairo, Egypt), mouth wash (DG-wash, Al Esraa Pharmaceuticals, Fourth Industrial Zone, Badr Industrial City, Cairo, Egypt), and anti-inflammatory (Cataflam 75mg amp, Novartis Pharma, Heliopolis, Cairo, Egypt).

\section{Surgical procedures:}

- Inferior alveolar nerve block and field block techniques were used to anaesthetize the surgical field using 4\% Articaine / adrenaline 1:100,000 $1.8 \mathrm{ml}\left(3 \mathrm{M}^{\mathrm{TM}}\right.$ ESPE $^{\mathrm{TM}}$ Ubistesin $^{\mathrm{TM}}$ Forte, $3 \mathrm{M}$ Germany)

- After Local anesthesia administration, a midcrestal incision on the edentulous ridge was done. Partial full thickness mucoperiosteal flap was raised with minimal tissue reflection on the buccal and lingual aspects of cortical plates to preserve the periosteum attachment surrounding the buccal and lingual bone. This was performed to prevent possible buccal and lingual bone plate crack.

- Using a piezosurgical device Piezotome SOLO (Satelec Acteon, Bordeaux-Merignac, France), a crestal corticotomy cut was made in the alveolar ridge. Then, this crestal corticotomy cut widened till depth of splitting reached to $5 \mathrm{~mm}$.

- On the mesial and distal ends of the corticotomy (2 $\mathrm{mm}$ away from adjacent teeth), vertical 
cuts were made on the buccal cortex to a corresponding depth. Then the buccal bone plate was distracted step by step (fig.1b )

- Then implant site was prepared with the superior border of fixture was positioned at the level of the alveolar ridge crest. Zimmer implant ${ }^{\circledR}$ (Zimmer dental, 1900 Aston Avenue Carlsbad, CA 92008-7308.USA) was used in this study. Implant diameter ranged from 4.2 to $4.8 \mathrm{~mm}$ while implant length ranged from 8 to $12 \mathrm{~mm}$. By using Osstell TM, primary stability recorded for all fixtures (fig.1.c\&d).

- In group I, the remaining distraction gap wasn't filled with any material. While in group II, the remaining distraction-gap was filled with osteon II collagen and in group III, the remaining distraction-gap was filled with osteon II collagen mixed by HyA (fig.1.e \&f). Then distracted site was covered by collagen membrane ((GENOSS Collagen Membrane, Dentium. Co. Ltd, Suwon, South Korea) in all groups (fig.1.g).

- The final wound closure performed by interrupted 0/4 non-resorbable sutures (fig.1.h)

- Standard post-surgical instructions and medications were given to the patients as the preoperative therapy for 7 days and chlorhexidine mouth rinsing for 15 days. The patients were instructed to avoid incising food in the operated sites for 6 weeks.

- Sutures were removed between 10 and 14 days after surgery and all patients recurrently checked for any complications every 4 weeks.

- After 6 months, submerged healing period, the patients were called back for the second stage surgery. Definitive abutments were tightened using $35 \mathrm{Ncm}$ torques. The final prostheses made porcelain were cemented with resin cement (fig.1.i).

\section{Postoperative evaluation:}

\section{1-Clinical Evaluation}

- Probing Depth (PD): It was measured as the distance from the crest of gingival margin to the bottom of the gingival sulcus at four sites around implants using a Williams probe.

- Changes in Implant Stability Quotient (ISQ): By using Osstell TM, primary stability recorded. ISQ values taken immediately after implant placement were measured in triplicate and averaged to yield the mean baseline ISQ value for each implant. Additional Resonance frequency analysis (RFA) measurements were taken at the 6 months follow-up reentry for prosthetic procedures.

\section{2- Radiographic Evaluation:}

A. Post-operative ridge width: it was measured and compared with preoperative CBCT measurements (fig 2a,b\&c).

\section{B. Measuring of marginal bone loss:}

Implant marginal bone loss around the implant was evaluated using periapical that were taken on the day of the implant placement (baseline) and on the follow-up visits at 3, 6, and 12 month. The distance from a reference point at the implant to the most coronal point where the marginal bone contacts the implant was measure. Measurements were made mesially and distally for each implant.

\section{Measuring of bone density:}

Average density is determined at marginal and crestal bone around implant using Bioquant ${ }^{\circledR}$ (G Power, Ver. 3.192 copy right 1992-2014). In this software, Regions of Interest (ROI) was selected and traced (color density selection). A single pixel that represent a specific color (white pixels in radiographs) is selected or threshold allowing for 

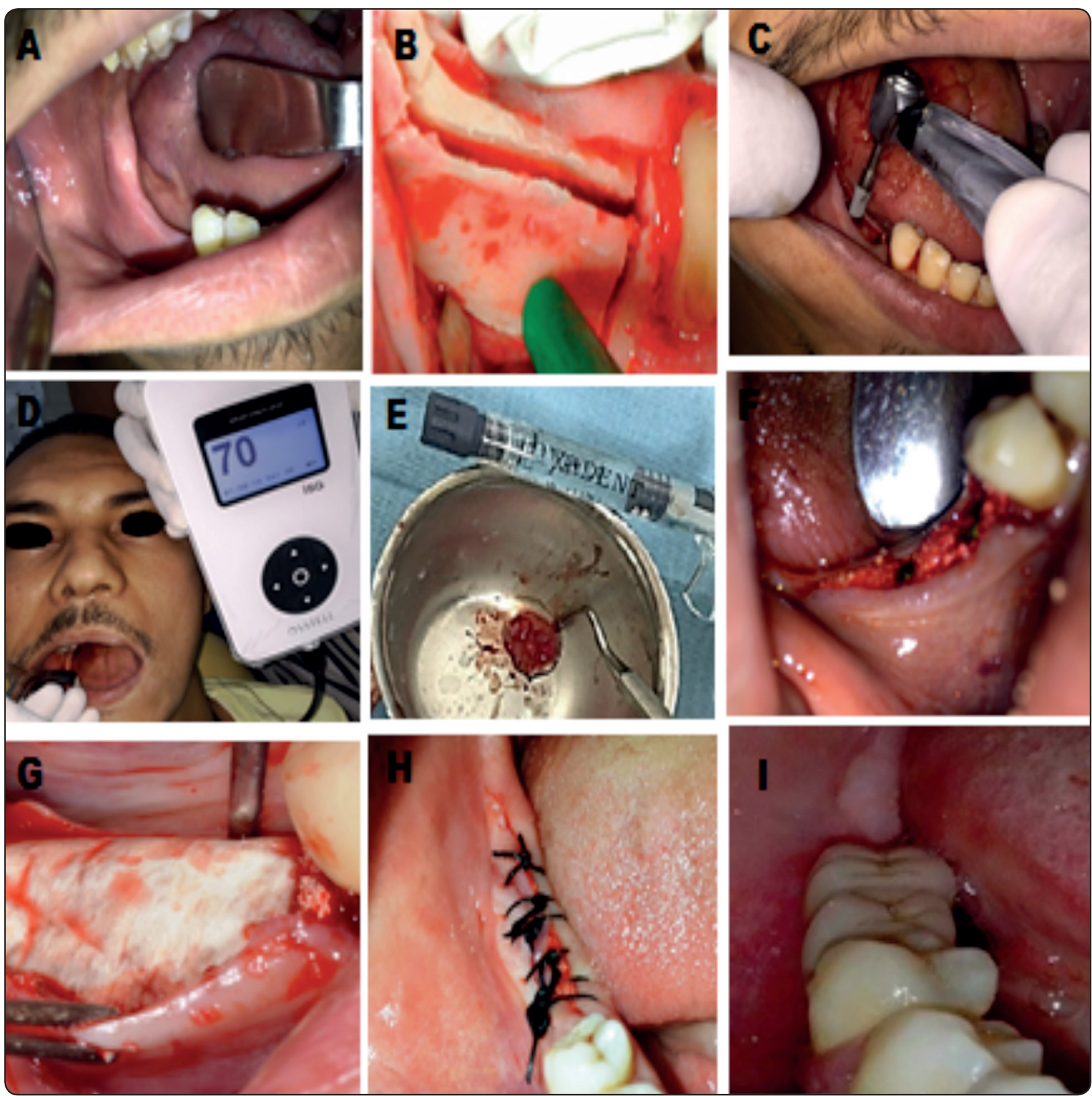

Fig. (1) a) Preoperative intraoral clinical photograph showing narrow posterior alveolar ridge b) Crestal incision and mucoperiosteal flap elevation with crestal and buccal corticotomy by piezotome device c) Dental implant insertion d) Evaluation initial stability by Osstell e) Mixture of osteon II collagen and HyA f) Packing of bone graft mixture in splitted alveolar ridge and around dental implant g) Collagen membrane covering osteon II collagen and HyA mixture and dental implant h) Suturing of mucoperiostel flap i) Clinical photograph after final prostheses.

automatic selection of all other pixels in the ROI that threshold areas are traced and counted as a number of pixels that can be calculated as a ratio of the whole ROI. Bone density was measured in the day of the implant placement (baseline) and on the follow-up visits at 3,6 , and 12 month.

\section{B. Statistical analysis}

The data were collected, tabulated and statistically analyzed by Statistical Package for Social Sciences (SPSS) version 13and Graphs were performed using the Microsoft Excel 2017 program. 


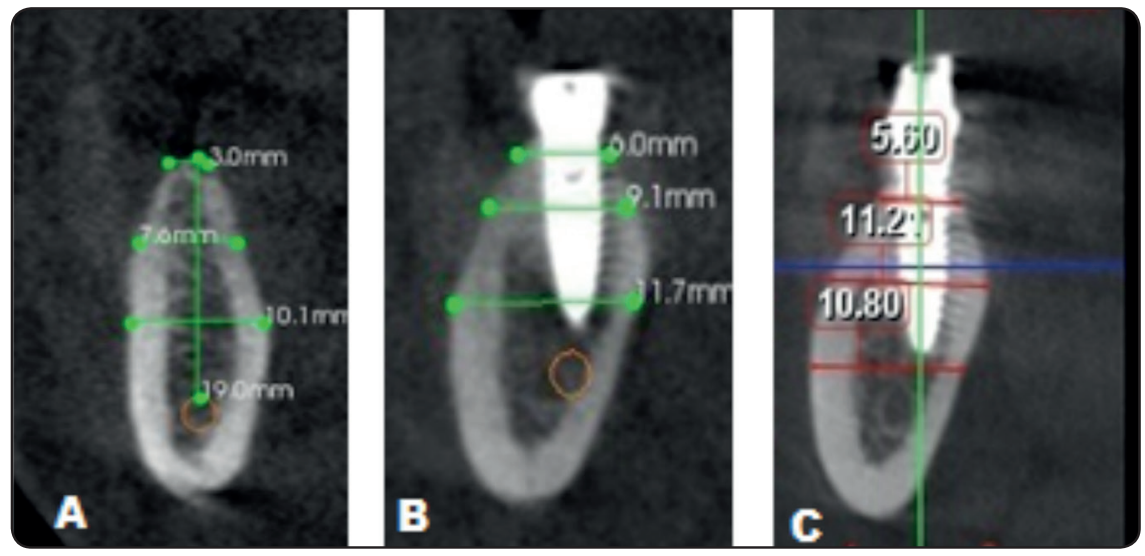

Fig. (2) CBCT showing measurements of alveolar ridge height and width a) Preoperatively b) Postoperatively after implant insertion immediatly c) postoperatively implant after 6 month

\section{RESULTS}

During the periods of the study, one out of twenty one patient showed mobility and per-implantitis and other one exhibited partial membrane exposure at the 14-day post-operative check, and re-entry was performed to cover the implant.

\section{Changes in Probing Depth measurement (PD)}

PD Measurements were increased gradually by the end of study in all groups. Group II and group III exhibited statistical significant difference at the 6th month and high statistical significant difference at the $12^{\text {th }}$ month of observation period when compared to the 3rd month. While group I showed statistical difference at the $12^{\text {th }}$ month only. Unpaired-test used for comparing probing depth between groups, showed high statistical significant difference in the results of group III at the $12^{\text {th }}$ month of observation periods when compared with the other both groups ( table 1).

\section{Changes in Bone Density Measurements (BD)}

Paired t-test showed gradual elevation in bone density readings in all groups during the observation periods of the study. In group I the mean value of $\mathrm{BD}$ at baseline was $81.05 \pm 7.33$ that elevated to $92.17 \pm 8.4$ at the $12^{\text {th }}$ month of implant placement. In the same manner, the BD mean value of group II was $79.43 \pm 7.7$ at baseline that elevated to $100.71 \pm 7.1$ at the $12^{\text {th }}$ month after implant placement. While, in group III the mean value of BD at the base line showed dramatic value $132.14 \pm 7.2$ that decreased at the $3^{\text {rd }}$ month to be $104.21 \pm 6.9$ that elevated again to $117.09 \pm 5.2$ at the $12^{\text {th }}$ month after implant placement. Moreover, the difference within the groups was statistically significant at the $6^{\text {th }}$ month and highly statistical significant at the $12^{\text {th }}$ month when compared with the $3^{\text {rd }}$ month of observation period.

Unpaired-test illustrated high statistical difference in group III at the $6^{\text {th }}$ and $12^{\text {th }}$ month when compared with both group II and group I. In the same time group II showed highly statistical significant over group I at the $12^{\text {th }}$ month only (table 1 ).

\section{Changes in Marginal bone level (MBL):}

In the all groups the mean value of MBL was $0.00 \pm 0.00$ at baseline that increased to $0.58 \pm 0.07$ in group I and $0.22 \pm 0.06$ in group II and $0.09 \pm 0.02$ after 12 months of implant placement. The difference within the groups was high statistically significant at the $6^{\text {th }}$ and $12^{\text {th }}$ month in group III and at the $12^{\text {th }}$ month in group II when compared with the $3^{\text {rd }}$ month (table 1). Unpaired t-test for comparing between the groups presented that 
there are highly statistical significant difference in the results of group III at the 6 th and $12^{\text {th }}$ month when compared with group I and at the $12^{\text {th }}$ month only when compared with group II, while group II showed statistical significant difference over group I at the $12^{\text {th }}$ month (table 1).

\section{Changes in Implant Stability Quotient (ISQ):}

In all groups, Paired t-test showed statistical significant difference at the $6^{\text {th }}$ month of observation interval when compared to the baseline. Unpairedtest used for comparing ISQ between groups, showed statistical significant difference in group II and group III at the $6^{\text {th }}$ month when compared with group I, while there is no statistical significant difference between group III and group II ( table 2) .

\section{Changes in alveolar ridge width:}

In this study alveolar ridge width was increased in all groups. In group I the mean value of Alveolar ridge width was $4.47 \mathrm{~mm} \pm 0.9$ pre-operative that increased to be $6.74 \mathrm{~mm} \pm 1.1$ post-operative. In group II the mean value of Alveolar ridge width was $4.23 \mathrm{~mm} \pm 1.0$ pre-operative that increased to be $7.04 \mathrm{~mm} \pm 1.2$ post-operative. In group III the mean value of Alveolar ridge width was $4.51 \mathrm{~mm}$ \pm 1.2 pre-operative that increased to be $7.89 \mathrm{~mm} \pm 0.9$ post-operative. Unpaired-test, showed statistical significant difference in group II Vs. group I and highly statistical significant difference in group III Vs. group I \& group II post-operatively (table 2).

TABLE (1) Comparison between PD, BD \& MBL measurements of groups at different periods (between groups \& within group).

\begin{tabular}{|c|c|c|c|c|c|c|c|c|c|c|c|c|}
\hline & \multicolumn{4}{|c|}{ Group I } & \multicolumn{4}{|c|}{ Group II } & \multicolumn{4}{|c|}{ Group III } \\
\hline & \multicolumn{2}{|c|}{$6 \mathrm{mVs} 3 \mathrm{~m}$} & \multicolumn{2}{|c|}{$12 \mathrm{mVs} 3 \mathrm{~m}$} & \multicolumn{2}{|c|}{$6 \mathrm{mVs} 3 \mathrm{~m}$} & \multicolumn{2}{|c|}{$12 \mathrm{mVs} 3 \mathrm{~m}$} & \multicolumn{2}{|c|}{$6 \mathrm{mVs} 3 \mathrm{~m}$} & \multicolumn{2}{|c|}{$12 \mathrm{mVs} 3 \mathrm{~m}$} \\
\hline & $\mathrm{t}$ & $\mathrm{P}$ & $\mathrm{T}$ & $\mathrm{P}$ & $\mathrm{T}$ & $\mathrm{P}$ & $\mathrm{T}$ & $\mathrm{P}$ & $\mathrm{T}$ & $\mathrm{P}$ & $\mathrm{t}$ & $\mathrm{P}$ \\
\hline Probing depth & 2.1 & 0.053 & 2.3 & $0.048^{*}$ & 2.2 & $0.029 *$ & 2.3 & $0.008 * *$ & 2.1 & $0.01 *$ & 2.4 & $0.000 * *$ \\
\hline Bone Density & 7.4 & $0.041 *$ & 7.9 & $0.008 * *$ & 8.2 & $0.009 * *$ & 8.3 & $0.000 * *$ & 8.5 & $0.032 *$ & 8.8 & $0.000 * *$ \\
\hline \multirow[t]{4}{*}{ Marginal bone loss } & 1.8 & 0.067 & 1.7 & $0.046^{*}$ & 1.8 & $0.011 *$ & 1.9 & $0.006 * *$ & 2 & $0.000 * *$ & 1.9 & $0.000 * *$ \\
\hline & \multicolumn{4}{|c|}{ Group II Vs. Group I } & \multicolumn{4}{|c|}{ Group III Vs. Group II } & \multicolumn{4}{|c|}{ Group III Vs. Group I } \\
\hline & \multicolumn{2}{|c|}{$6 \mathrm{~m}$} & \multicolumn{2}{|c|}{$12 \mathrm{~m}$} & \multicolumn{2}{|c|}{$6 \mathrm{~m}$} & \multicolumn{2}{|c|}{$12 \mathrm{~m}$} & \multicolumn{2}{|r|}{$6 m$} & \multicolumn{2}{|c|}{$12 \mathrm{~m}$} \\
\hline & $\mathrm{t}$ & $\mathrm{P}$ & $\mathrm{T}$ & $\mathrm{P}$ & $\mathrm{T}$ & $\mathrm{P}$ & $\mathrm{T}$ & $\mathrm{P}$ & $\mathrm{t}$ & $\mathrm{P}$ & $\mathrm{T}$ & $\mathrm{P}$ \\
\hline Probing depth & 1.9 & 0.062 & 2 & $0.007 * *$ & 1.8 & $0.036^{*}$ & 1.9 & $0.000 * *$ & 2.1 & $0.000 * *$ & 2.1 & $0.000 * *$ \\
\hline Bone Density & 8.4 & 0.053 & 8.2 & $0.002 * *$ & 8.5 & $0.000 * *$ & 8.4 & $0.000 * *$ & 8.1 & $0.000 * *$ & 8.7 & $0.000 * *$ \\
\hline Marginal bone loss & 1.6 & $0.049 *$ & 1.7 & $0.017 *$ & 1.9 & $0.039 *$ & 1.7 & $0.000 * *$ & 1.8 & $0.000 * *$ & 1.9 & $0.000 * *$ \\
\hline
\end{tabular}

*Statistically significant: $(P<0.05) . \quad$ **High statistically significant: $(P<0.01)$. 
Table 2: Comparison between ISQ scores \& Alveolar ridge width measurements of groups at different periods (between groups \& within group).

\begin{tabular}{|c|c|c|c|c|c|c|}
\hline & \multicolumn{2}{|c|}{ Group I } & \multicolumn{2}{|c|}{ Group II } & \multicolumn{2}{|c|}{ Group III } \\
\hline & $\mathbf{T}$ & $\mathbf{P}$ & $\mathbf{T}$ & $\mathbf{P}$ & $\mathbf{T}$ & $\mathbf{P}$ \\
\hline \multirow[t]{2}{*}{ ISQ scores } & \multicolumn{2}{|c|}{6 Month Vs. Baseline } & \multicolumn{2}{|c|}{6 Month Vs. Baseline } & \multicolumn{2}{|c|}{6 Month Vs. Baseline } \\
\hline & 6.5 & $0.015^{*}$ & 6.8 & $0.012 *$ & 6.3 & $0.048^{*}$ \\
\hline \multirow[t]{2}{*}{ Alveolar ridge width } & \multicolumn{2}{|c|}{ Post- Vs. Pre-operative } & \multicolumn{2}{|c|}{ Post- Vs. Pre-operative } & \multicolumn{2}{|c|}{ Post- Vs. Pre-operative } \\
\hline & 2.4 & $0.000 * *$ & 2.4 & $0.000 * *$ & 2.3 & $0.000 * *$ \\
\hline
\end{tabular}

\begin{tabular}{|c|c|c|c|c|c|c|c|c|c|c|c|c|}
\hline \multirow{4}{*}{ ISQ scores } & \multicolumn{4}{|c|}{ Group II Vs. Group I } & \multicolumn{4}{|c|}{ Group III Vs. Group II } & \multicolumn{4}{|c|}{ Group III Vs. Group I } \\
\hline & \multicolumn{2}{|c|}{ Baseline } & \multicolumn{2}{|c|}{6 Month } & \multicolumn{2}{|c|}{ Baseline } & \multicolumn{2}{|c|}{6 Month } & \multicolumn{2}{|c|}{ Baseline } & \multicolumn{2}{|c|}{6 Month } \\
\hline & $\mathbf{T}$ & $\mathbf{P}$ & $\mathbf{T}$ & $\mathbf{P}$ & $\mathbf{t}$ & $\mathbf{p}$ & $\mathbf{t}$ & $\mathbf{P}$ & $\mathbf{T}$ & $\mathbf{P}$ & $\mathbf{t}$ & $\mathbf{P}$ \\
\hline & 6.5 & 0.56 & 6.3 & $0.044^{*}$ & 7.1 & 0.69 & 6.8 & 0.82 & 6.8 & 0.5 & 6.7 & $0.036^{*}$ \\
\hline \multirow{3}{*}{$\begin{array}{l}\text { Alveolar ridge } \\
\text { width }\end{array}$} & \multicolumn{2}{|c|}{ Pre. } & \multicolumn{2}{|r|}{ Post. } & \multicolumn{2}{|r|}{ Pre. } & \multicolumn{2}{|r|}{ Post. } & \multicolumn{2}{|c|}{ Pre. } & \multicolumn{2}{|c|}{ Post. } \\
\hline & $\mathbf{t}$ & $\mathbf{P}$ & $\mathbf{t}$ & $\mathbf{P}$ & $\mathbf{t}$ & $\mathbf{p}$ & $\mathbf{t}$ & $\mathbf{P}$ & $\mathbf{T}$ & $\mathbf{P}$ & $\mathbf{t}$ & $\mathbf{P}$ \\
\hline & 2.1 & 0.05 & 2.4 & $0.015^{*}$ & 2 & 0.06 & 2.5 & $0.009 * *$ & 2.1 & 0.09 & 2.4 & $0.000^{* *}$ \\
\hline
\end{tabular}

*Statistically significant: $(P<0.05) . \quad{ }^{*}$ High statistically significant: $(P<0.01)$.

\section{DISCUSSION}

One major drawback of alveolar bone splitting is the risk for bone resorption due to malnutrition of the laterally out displaced buccal bone wall ${ }^{(12)}$. Although some approaches were proposed to reduce bone resorption evidence for their efficacy is still lacking ${ }^{(13,14)}$. Current study used a mixture of HyA with Osteon II collagen to fill distracted gap and to decrease bone resorption after RST through to benefit from regenerative proprieties of HyA.

The present study used Osteon II collagen which is a newly developed alloplastic material containing $70 \%$ HA and 30\%b- TCP which are quite close to major mineral components of the human bone ${ }^{(15-}$ ${ }^{17)}$. Moreover, bovine type I collagen was added to Osteon II material to increase its osteoconductivity - Where, the collagen is absorbed slowly over several weeks after helping the initial shaping ${ }^{(11)}$. This matched with Bae JH et al. ${ }^{(21)}$ who found that the advantage of combining an insoluble HA with a resorbable $\beta$-TCP is that the slow-resorbing HA will maintain the volume, while faster-resorbing $\beta$-TCP will promote bone regeneration.

In the present study Hyaluronic acid was used in mixture with Osteon II collagen. Because of it has osteoconductive potential; it accelerates the bone regeneration by means of chemotaxis, proliferation and successive differentiation of mesenchyme cells ${ }^{(20)}$.

Accordingly, the aim of current study was to investigate successful enhancement effect of Osteon II collagen with HyA on osseointegration around dental implant in distracted gap. Clinical as well as radiological results after one year revealed stable hard and soft tissue conditions with no soft tissue recessions or peri-implant bone loss in groups II \& III with superiority for group III.

No evidence of post-operative infection was noticed in this study. This may be due to the application of sterile surgical procedure and the use of antibiotic during postoperative and bacteriostatic effect of HyA. This is in the same side with Pirnazar 
et al (22) study conclusion that stated at clinical application of HyA gels may reduce the bacterial contamination of surgical wound site, thereby, lessening the risk of post-surgical infection and promoting more predictable bone generation.

In the present study, PPD measurement showed that no statistical significant difference between groups during at 3,6 and 12 month observation periods. In the same side, ISQ test showed no statistical significant difference during at baseline and 6 month observation periods. These results can be explained by that all groups had the same technique which preserve on soft tissue and blood supply at distracted site when piezosurgical device used to preparation of bone cut. This explanation match with Kshirsagar et $\mathrm{al}^{(23)}$ conclusion that pointed to the piezosurgical device provides extreme precision on micrometric cutting, safety as well as, the device causes minimal bleeding during and after the operative procedure and the healing process is shorter.

Another explanation is usage of collagen membrane to cover surgical area under soft tissue flaps in all groups which prevented the apical migration of epithelium and supported new connective tissue attachment and tissue regeneration that demonstrated by Dimitriou et al ${ }^{(24)}$ study.

On the other side, bone density measurements showed group III had highly statistical significant difference at all intervals when it was compared with group I, also it showed statistical difference at 6 month and highly statistical significant difference at 9 and 12 months when it was compared with group II. While, Marginal bone level values showed that there are high statistical significant difference during 12 month interval when group III was compared with group II.

These results were agreed with Kim et al. ${ }^{(25)}$ that applied HyA to fresh extraction sockets with previous pathology. They found out that HyA, because of its osteoinductive, bacteriostatic, and anti- inflammatory properties, may improve bone formation and accelerate wound healing in infected sockets. Also, these results matched with Aslan et $a l .^{(26)}$ who demonstrated that the Osteon II collagen with hyaluronic acid groups has superiority bone healing histologically. On the other hand, Eric Aguado et al. ${ }^{(19)}$ investigated the use of hyaluronic acid (HyA) as an aqueous binder of the $\beta$ - TCP bone graft granules. On contrary to our results, they found out that the amount of formed bone was not significantly higher than with $\beta$ - TCP granules alone.

The positive results obtained in association with group III in all of the observation periods suggest a superior effect of HyA and rapid start of bone formation when used in association with Osteon II collagen as a bone graft than if used alone.

\section{CONCLUSION}

According to results of the present study can be concluded that a mixture of Osteon II collagen with HyA have highly regenerative effect than Osteon II collagen alone that lead to accelerate osseointegration around dental implant, decrease bone resorption after RST and increase bone density of alveolar ridge.

\section{REFERENCES}

1- Esposito M, Grusovin MG, Willings M, Coulthard P, Worthington HV. The effectiveness of immediate, early, and conventional loading of dental implants: A Cochrane systematic reviewof randomized controlled clinical trials. International Journal of Oral Maxillofacial Implants. 2007; 22: 893-904.

2- Jensen J, Sindet-Pedersen S, Oliver AJ. Varying treatment strategies for reconstruction of maxillary atrophy with implant: results in 98 patients. J Oral Maxillofac Surg. 1994;52:210-6.

3- Hammerle CHR, Jung RE, Feloutzis A. A systematic review of the survival of implants in bone sites augmented with barrier membranes (guided bone regeneration) in partially edentulous patients. J Clin Periodontol.2002; 29:226-31. 
4- Castillo R. Horizontal ridge augmentation before placing implants using a double-bone, double resorbable membrane technique: Two clinical cases. Eur J Esthet Dent 2010; 5:340-56.

-5 Aghaloo TL, Moy PK. Which hard tissue augmentation techniques are the most successful in furnishing bony support for implant placement? Int J Oral Maxillofac Implants 2007;22:49-70.

6- Jensen SS, Terheyden H. Bone augmentation procedures in localized defects in the alveolar ridge: Clinical results with different bone grafts and bone-substitute materials. Int $\mathbf{J}$ Oral Maxillofac Implants 2009; 24:218-36.

7- Donos N, Mardas N, Chadha V. Clinical outcomes of implants following lateral bone augmentation: Systematic assessment of available options (barrier membranes, bone grafts, split osteotomy). Journal of Clinical Periodontology. 2008; 35: 173-202.

8- Demarosi F, Leghissa GC, Sardella A, Lodi G, Carrassi A. Localised maxillary ridge expansion with simultaneous implant placement: A case series. British Journal of Oral \& Maxillofacial Surgery. 2009; 47: 535-40.

9- Simion M, Baldoni M, Zaffe D. Jawbone enlargement using immediate implant placement associated with a split-crest technique and guided tissue regeneration. International Journal of Periodontics \& Restorative Dentistry. 1992; 12: 462-73.

10- Han JY, Shin SI, Herr Y, Kwon YH, Chung JH. The effects of bone grafting material and a collagen membrane in the ridge splitting technique: An experimental study in dogs. Clin Oral Implants Res 2011;22:1391-8.

11- Sethi A, Kaus T. Maxillary ridge expansion with simultaneous implant placement: 5-year results of an ongoing clinical study. International Journal of Oral Maxillofacial Implants. 2000; 15: 491-9.

12- Scipioni A, Bruschi GB, Giargia M, Berglundh T, Lindhe J. Healing at implants with and without primary bone contact. An experimental study in dogs. Clinical Oral Implants Research. 1997; 8: 39-47.

13- Basa S, Varol A, Turker N. Alternative bone expansion technique for immediate placement of implants in the edentulous posterior mandibular ridge: A clinical report. International Journal of Oral \& Maxillofacial Implants. 2004; 19: 554-8.

14- Coatoam GW, Mariotti A. The segmental ridge-split procedure. Journal of Periodontology. 2003; 74: 757-70.
15- Kim YK.,Yun PY., Lim SC., Kim SG .\& Lee HJ,Ong JL. Clinical evaluation of Osteon as anew alloplastic material in sinus bome grafting and its effect on bone healing. $\mathrm{J}$ Biomed. Mat. Res. B Appl Biometer 2008;86:270-7.

16- Keating J.F \& McQueen M.M. Substitutes for autologous bone graft in orthopedic trauma. J Bone Joint Surg Br.2001;83(1):3-8 .

17- Lee EU, Kim DJ, Lim HC, Lee JS, Jung UW, Choi SH. Comparative evaluation of biphasic calcium phosphate and biphasic calcium phosphate collagen composite on osteoconductive potency in rabbit calvarial defect. Biomaterials Research. 2015; 19: 1-7.

18- Shamma1 MM, Ayad SS, El-dibany RM , Nagui DA. evaluation of the effect of hyaluronic acid mixed with biphasic calcium phosphate on bone healing around dental implants (experimental study). ADJ 2017;.42:104-11.

19- Aguado E, Florence P, Christine G, Eric G, Daniel C. $\beta$ TCP granules mixed with reticulated hyaluronic acid induces an increase in bone apposition. Biomed Mater. 2013; 9(1): 015001.

20- Bansal J., Kedige SD.\& Anand S. Hyaluronic acid: a promising mediator for periodontal regeneration. Indian $\mathrm{J}$ Dent Res. 2010; 21(4):575-8.

21- Bae JH, Kim YK, Kim SG, Yun PY, Kim JS. Sinus bone graft using new alloplastic bone graft material (Osteon)-II: clinical evaluation. Oral Surg Oral Med Oral Radiol Endod 2010; 109:14-20.

22- Pirnazar P., Wolinsky L., Nachnani S., Haake S., Pilloni A.\& Bernard GW. Bacteriostatic effects of hyaluronic acid. J periodontal. 1999; 70(4):370-4.

23- Kshirsagar JT, Prem kumar K, Yashodha SR, Nirmmal Maria T. Piezosurgery: Ultrasonic bone surgery in periodontics and oral implantology- Review. IJADS 2015; 1(5): 19-22.

24- Rozalia Dimitriou., George I Mataliotakis., Giorgio Maria Calori eter V Giannoudis Email author Contri equally. The role of barrier membranes for guided bone regeneration and restoration of large bone defects: current experimental and clinicalevidence. BMC Medicine 2012;10:81.

25- Kim JJ, Song HY, Ben Amara H, Kyung-Rim K, Koo KT. Hyaluronic Acid Improves Bone Formation in Extraction Sockets with Chronic Pathology: A Pilot Study in Dogs. J Periodontol. 2016; 87(7): 790-5.

26- Aslan M.,Simsek G. \& Dayi E. The effect of hyaluronic acid-supplemented bone graft in bone healing: experimental study in rabbits. J Biomater Appl. 2006; 20(3):209-20. 